\title{
Spermatozoan numbers and testicular characteristics of male white-tailed deer fawns during the mating season
}

\author{
John D. PELES, Olin E. RHODES Jr and Michael H. SMITH
}

Peles J. D., Rhodes O. E. Jr and Smith M. H. 2000. Spermatozoan numbers and testicular characteristics of male white-tailed deer fawns during the mating season. Acta Theriologica 45: 95-102.

Testicular spermatozoan numbers, testes weight, testes length, body weight, and kidney fat index (KFI) were obtained for male white-tailed deer Odocoileus virginianus (Zimmerman, 1780) fawns during the mating season at the Savannah River Site (SRS) in South Carolina. Mean values for testicular spermatozoa, testes weight, and testes length increased significantly over the study period (late October - late December) whereas body weight and KFI did not change with time. Testicular spermatozoa were found in $28 \%$ of all fawns examined and the proportion of sexually mature fawns increased greatly over the course of the study and was highest during December. These findings suggest that male fawns breed later than adults at a time that coincides with the mean conception date in doe fawns. Testes weight, testes length, body weight, and KFI were significantly greater in fawns with testicular spermatozoa compared to those without testicular spermatozoa. We suggest that testes weight is closely associated with the presence of testicular spermatozoa in fawns from SRS.

Savannah River Ecology Laboratory, Drawer E, Aiken, SC 29802, USA, e-mail: peles@srel.edu (JDP and MHS); Department of Forestry and Natural Resources, 1159 Forestry Building, Purdue University, West Lafayette, IN 47907, USA (OER)

Key words: Odocoileus virginianus, spermatozoa, testes, body weight, kidney fat index, fawns

\section{Introduction}

Knowledge of the reproductive capabilities of all age groups in a population is essential for the development of appropriate management strategies for any wildlife species. For example, in some situations white-tailed deer Odocoileus virginianus (Zimmerman, 1780) fawns may represent an important component of breeding populations (Schultz and Johnson 1992). Doe fawns commonly breed on the Savannah River Site (SRS) in South Carolina (Urbston 1967, 1976). Several investigators have described breeding and reproductive characteristics of doe fawns at SRS (Urbston 1967, Johns et al. 1977, Rhodes et al. 1986, 1991, Johns 1994).

Although much less data exist regarding reproduction in male fawns than in female fawns, studies conducted in enclosed populations have demonstrated that male fawns are capable of breeding successfully (Lambiase et al. 1972, Schultz and Johnson 1992). However, only two studies to date have examined reproductive characteristics of male fawns in free-ranging populations from temperate regions 
(Urbston 1976, Scanlon and Lenker 1983) and no studies have examined the timing of reproduction in this age class. Thus, more information regarding reproductive characteristics of male fawns during the mating season is needed to assess the potential contribution of this age class to breeding populations, such as the deer herd at SRS.

The purpose of this investigation was to describe short-term changes in reproductive and physical characteristics of male fawns during the mating season. Specifically, we examined the effects of time on testicular spermatozoa numbers, testes weight, testes length, body weight, and kidney fat index (KFI) of male fawns during the mating season. We also examined the potential influence of testicular characteristics, body weight and KFI on the ability of fawns to reach puberty.

\section{Methods}

Reproductive characteristics were determined for 173 male white-tailed deer fawns harvested during managed hunts at the Savannah River Site (SRS). Fawns were distinguished from other age classes based on the pattern of toothwear and eruption (Severinghaus 1949). Hunts were conducted twice weekly from 27 October - 29 December 1984. Body weight, paired testes weight, and paired testes length were determined for each harvested deer. Kidneys and perirenal fat were removed from each individual following the procedure of Riney (1955). The weight of perirenal fat (both kidneys combined) was divided by total kidney weight and multiplied by 100 to obtain a kidney fat index (KFI; Finger et al. 1981).

Testicular spermatozoan numbers were estimated using the procedure of Amann and Almquist (1961). The right and left testes of each individual were each homogenized separately in $200 \mathrm{ml}$ of a $0.9 \% \mathrm{NaCl}$ solution containing $0.05 \%$ Triton X-100. Aliquots were then obtained from each homogenate and the number of spermatozoa were counted using a hemocytometer. Spermatozoa from each homogenate were counted on six hemocytometer slides and the mean of these counts was used to estimate the total number of spermatozoa present in the homogenate. Testicular spermatozoa were reported as number per paired testes.

The nine-week investigation was divided into three time periods (Period $1=27$ October -14 November, Period $2=17$ November -5 December, Period $3=8-29$ December). One-way analysis of variance (ANOVA) was used to examine the effects of time on testicular spermatozoa, paired testes weight, paired testes length, body weight, and KFI (log transformed). The Bonferroni-Dunn Procedure was used for separation of means where appropriate. Contingency chi-square analysis was used to determine whether the proportion of fawns with testicular spermatozoa differed among time periods. Student's $t$-tests were used to compare mean testes weight, testes length, body weight, and KFI between fawns with testicular spermatozoa and those without testicular spermatozoa.

Paired Student's $t$-tests were used to compare differences in testicular spermatozoa (mature fawns only), testes weight, and testes length between the right and left portions of the reproductive tract. For each fawn with testicular spermatozoa, estimates of mean spermatozoan numbers were calculated based on 2, 3, 4, 5, and 6 counts for each testis. Estimates based on these counts were compared using repeated-measures ANOVA to determine the number of aliquots needed to obtain reliable estimates of spermatozaon numbers in fawns.

\section{Results}

Mean testicular spermatozoa $(F=5.45, p=0.005)$, testes weight $(F=6.72, p=$ $0.002)$, and testes length $(F=7.24, p=0.001)$ of fawns differed significantly among 
Table 1. Mean $( \pm \mathrm{SE})$ values for testicular spermatozoa $\left(\times 10^{9}\right)$, paired testes weight $(\mathrm{g})$, paired testes length $(\mathrm{mm})$, body weight $(\mathrm{kg})$, and kidney fat index (KFI; untransformed) of white-tailed deer fawns on the Savannah River Site during three time periods (27 October - 14 November, 17 November - 5 December, and 8-29 December) in 1984. Sample sizes are given in parentheses. Means with different letters are significantly different (Bonferroni-Dunn Test, $p<0.05$ ) among time periods.

\begin{tabular}{lccc}
\hline Characteristic & Period 1 & Period 2 & Period 3 \\
\hline Testicular spermatozoa & $0.001 \pm 0.001^{\mathrm{a}}$ & $0.043 \pm 0.021^{\mathrm{a}}$ & $0.290 \pm 0.106^{\mathrm{b}}$ \\
& $(62)$ & $(51)$ & $(60)$ \\
Testes weight & $12.6 \pm 0.8^{\mathrm{a}}$ & $16.9 \pm 1.6^{\mathrm{b}}$ & $18.4 \pm 1.3^{\mathrm{c}}$ \\
& $(62)$ & $(48)$ & $(60)$ \\
Testes length & $72.6 \pm 1.6^{\mathrm{a}}$ & $79.8 \pm 2.4^{\mathrm{b}}$ & $82.6 \pm 2.1^{\mathrm{b}}$ \\
& $(62)$ & $(48)$ & $(60)$ \\
Body weight & $28.5 \pm 0.6^{\mathrm{a}}$ & $28.5 \pm 0.7^{\mathrm{a}}$ & $30.2 \pm 0.6^{\mathrm{a}}$ \\
& $(62)$ & $(51)$ & $(60)$ \\
KFI & $15.7 \pm 1.1^{\mathrm{a}}$ & $20.5 \pm 1.1^{\mathrm{b}}$ & $19.0 \pm 1.1^{\mathrm{b}}$ \\
& $(57)$ & $(50)$ & $(57)$ \\
\hline
\end{tabular}

time periods, whereas no significant effect of time was observed for mean body weight $(F=1.94, p>0.05)$ or KFI values $(F=2.56, p>0.05)$. In general, values for all reproductive characteristics (Table 1 ) increased over time and were significantly higher in Period 3 compared to Period 1. In addition, testicular spermatozoan numbers increased significantly between Periods 2 and 3 , testes length increased significantly between Periods 1 and 2 , and testes weight increased significantly among all time periods.

Testicular spermatozoa were found in $28 \%$ (48 of 173) of all fawns examined. The proportion of fawns with testicular spermatozoa differed significantly among time periods (Period $1=0.06$, Period $2=0.24$, Period $3=0.55 ; \chi^{2}=36.24, p=$ $0.001)$. Mean values for testes weight $(t=-12.53, p<0.001)$, testes length $(t=$ 10.76, $p<0.001)$, body weight $(t=-6.01, p<0.001)$, and KFI $(t=-2, p=0.04)$ were significantly greater in fawns with testicular spermatozoa compared to those without (Table 2). The percentage of fawns with testicular spermatozoa increased steadily among weight classes (Fig. 1A). Although the percentage of fawns reaching puberty also increased over KFI classes (Fig. 1B), a relatively large percentage of fawns in the highest KFI class were without testicular spermatozoa.

Significant differences were observed between the right and left sides of the reproductive tract regarding testes weight $(t=-3.32, p=0.001$, left $>$ right $)$ and testes length ( $t=-6.41, p<0.001$, left $>$ right). However, testicular spermatozoan numbers of fawns did not differ significantly between the right and left sides of the reproductive tract $(t=-1.35, p>0.05)$. No significant differences were observed among estimates of mean testicular spermatozoan numbers based on $2,3,4,5$, and 6 counts per testis $(F=1.51, p>0.05)$. 
Table 2. Mean values $( \pm \mathrm{SE})$ for paired testes weight $(\mathrm{g})$, paired testes length $(\mathrm{mm})$, body weight $(\mathrm{kg})$, and kidney fat index (KFI; untransformed) of white-tailed deer fawns with and without testicular spermatozoa on the Savannah River Site during 27 October - 29 December 1984. Means are also given for all fawns combined. Sample sizes are given in parentheses. Mean values for each characteristic differed significantly between fawns with and without testicular spermatozoa in all cases ( $t$-test, $p<0.001)$

\begin{tabular}{lccc}
\hline Characteristic & $\begin{array}{c}\text { Fawns with testicular } \\
\text { spermatozoa }\end{array}$ & $\begin{array}{c}\text { Fawns without testicular } \\
\text { spermatozoa }\end{array}$ & All fawns \\
\hline Testes weight & $23.0 \pm 1.0$ & $11.4 \pm 0.4$ & $14.8 \pm 0.6$ \\
& $(47)$ & $(118)$ & $(165)$ \\
Testes length & $91.2 \pm 1.4$ & $71.1 \pm 1.1$ & $76.8 \pm 1.1$ \\
& $(47)$ & $(117)$ & $(164)$ \\
Body weight & $32.4 \pm 0.6$ & $27.8 \pm 0.4$ & $29.0 \pm 0.4$ \\
& $(49)$ & $(124)$ & $(173)$ \\
KFI & $20.9 \pm 1.2$ & $17.2 \pm 1.1$ & $18.2 \pm 1.2$ \\
& $(47)$ & $(117)$ & $(164)$ \\
\hline
\end{tabular}
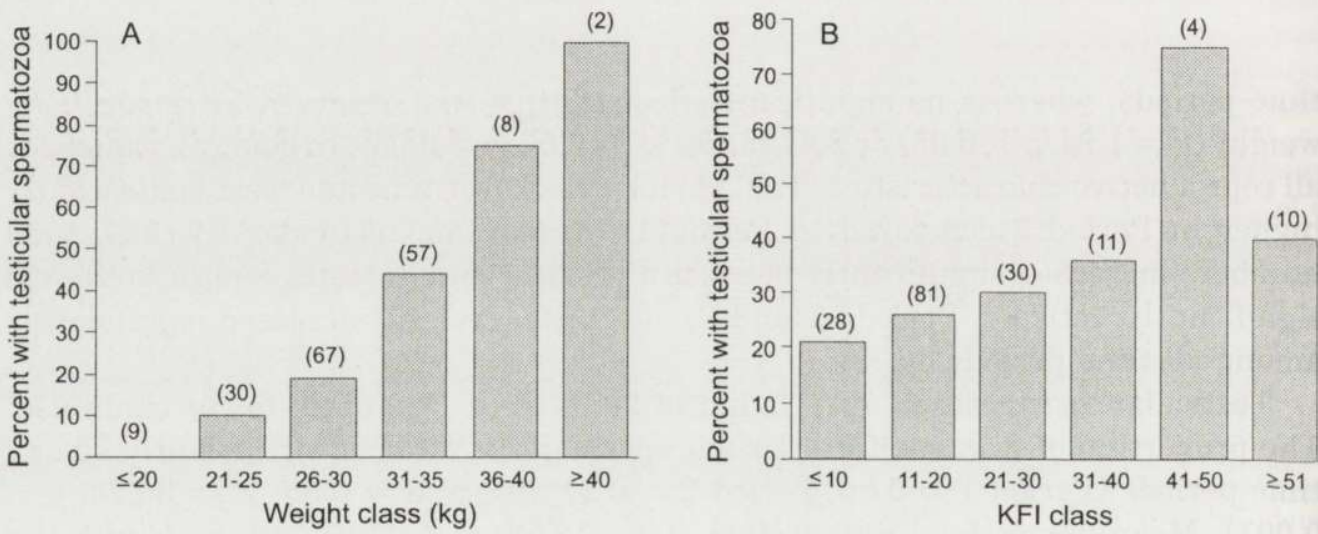

Fig. 1. Percent of male white-tailed deer fawns in each (A) weight class and (B) kidney fat index (KFI) class that had testicular spermatozoa. Fawns were collected from the Savannah River Site during 27 October - 29 December 1984. Sample sizes for each weight class are given in parentheses.

\section{Discussion}

In a previous investigation conducted at SRS, Scanlon and Lenker (1983) found testicular spermatozoa in 6 of 17 fawns examined during early November and early December. During a similar time period, Lambiase et al. (1972) obtained sperm from 8 of 10 of male fawns in an enclosed population. Our results support these findings and suggest that at least a portion of fawns in the SRS population reach 
puberty and have the potential to breed during their first year. This is important since breeding by male fawns may impact the population dynamics of some herds (Schultz and Johnson 1992), such as the one at SRS, where age structure has been skewed toward younger age classes by harvesting practices (Scribner et al. 1985).

Although our results indicate that some male fawns in the SRS herd can potentially breed, individuals in this age class may still be denied mating opportunities when dominant older males are present (Marchinton and Hirth 1984). However, when compared to previous observations of adults, our results regarding short-term changes in reproductive characteristics of fawns during the mating season suggest that fawns reach breeding condition much later than adult males. For example, spermatozoan numbers and testicular characteristics of adult males at SRS have been shown to decrease significantly over the same time period in which our study was conducted (M. H. Smith, unpubl. data). Miller et al. (1987) also demonstrated that testosterone levels of adults decrease significantly over this same time period. By breeding later than adult males, fawns may decrease the chances of competitive interactions with dominant older males and increase their chances of obtaining mating opportunities with available does. Data regarding mating activity by male fawns is necessary to test this hypothesis.

If male fawns in the SRS herd are able to successfully mate, we suggest that most breeding by these individuals likely takes place with females in the same age class. Nearly $40 \%$ of doe fawns at SRS breed, and conception in most of these fawns occurs between mid-December and mid-January at SRS (Johns et al. 1977, Rhodes et al. 1986). In contrast, adult does breed much earlier (mean conception date $=13$ November; Rhodes et al. 1986). In the present investigation, the proportion of male fawns with testicular spermatozoa was much higher during Period 3 (December) compared to the earlier time periods. These findings suggest that male fawns reach puberty at a time that coincides with the peak reproductive activity of female fawns.

Patterns of change in body weight and KFI of male fawns were similar to those observed in previous investigations (Johns et al. 1982, Johns et al. 1984). It is interesting to note that fat levels have been shown to increase in male fawns from July through December but decrease dramatically in adults during this time (Johns et al. 1982, Johns et al. 1984). This decline in fat levels among adults has been attributed to increased energy expenditures and decreased food intake during the breeding season (Johns et al. 1982, Johns et al. 1984). In addition, KFI values of male fawns have been shown to decrease between December and March. Although this decrease may be related to the energetic demands of growth and/or thermoregulation, there exists the possibility that KFI values may decrease as a result of breeding activity by fawns during this time period.

Results demonstrate that fawns with testicular spermatozoa differ from those without spermatozoa regarding testicular characteristics, body weight, and KFI (Table 2). Testes weight appears to be associated with the ability of fawns to reach puberty since the mean testes weight of fawns without spermatozoa was only $49.4 \%$ 
of the testes weight of fawns with testicular spermatozoa. Furthermore, the pattern of increase in testicular spermatozoa over time is similar to the pattern observed for testes weight. This increase in testes weight and subsequent increase in testicular spermatozoan numbers likely results from the initiation of spermatogenesis and increased activity of the semineferous tubules (Mirarchi et al. 1977) during the sexual maturation process.

Body weight has been shown to be an important factor influencing reproductive rate in doe fawns (Sauer 1984), and therefore, may also be related to the ability of male fawns to reach puberty. In the current investigation, no male fawns weighing less than $21 \mathrm{~kg}$ reached puberty, $80 \%$ of those in the $36-40 \mathrm{~kg}$ weight class reached puberty, and all individuals $>41 \mathrm{~kg}$ obtained puberty (Fig. 1A). In contrast, the percentage of fawns having testicular spermatozoa generally increased with increasing KFI values (Fig. 1B), but $60 \%$ of fawns in the highest KFI class did not reach puberty.

Although the proportion of fawns with testicular spermatozoa increased among weight classes, it is important to note that testicular spermatozoan numbers increased steadily with time but body weight did not differ significantly among time periods (Table 1). One possible explanation for these conflicting observations is that a threshold body weight may be necessary for the increased development of testicular characteristics and the initiation of spermatogenesis. Although body weight in male white-tailed deer increases over several years of life, the most rapid increase in body weight occurs during the first several months (Leberg et al. 1992). Thus, the observation that the proportion of fawns with testicular spermatozoa increased among weight classes may simply reflect a relationship between age and body weight.

The present investigation also provided an opportunity to address questions regarding methods used for examining reproductive characteristics in white-tailed deer. For example, our findings demonstrated that weight and length differ significantly between the right and left testes. These findings conflict with previous observations, (Scanlon and Lenker 1983) and suggest that the entire reproductive tract should be sampled to provide an accurate representation of reproductive characteristics. Our results also demonstrate that as few as two aliquots per testes are necessary to accurately estimate testicular spermatozoan numbers. This observation should save future investigators a great deal of time and effort when estimating spermatozoan numbers.

The study of reproduction in white-tailed deer fawns has important implications for the development of management programs where fawn breeding is expected to play a significant role. This includes situations where a large proportion of the adult males are harvested, captive breeding programs, or in deer introduction programs (Schultz and Johnson 1992). Management decisions for a particular deer herd should incorporate knowledge regarding age structure and the reproductive success of fawns in the herd. In herds where fawns are a potentially important component of the breeding population, management programs should give con- 
sideration to the factors that might potentially influence the ability of fawns to reach puberty.

Acknowledgments: This research was supported by contract DE-FC09-96SR18546 between the U.S. Department of Energy and the University of Georgia's Savannah River Ecology Laboratory. We thank B. H. Miller and P. E. Johns for assistance with data collection. Two anonymous reviewers provided constructive comments on an earlier version of this manuscript.

\section{References}

Amann R. P. and Almquist J. O. 1961. Reproductive capacity of dairy bulls. I. Technique for direct measurement of gonadal and extra-gonadal sperm reserves. Journal of Dairy Science 44: 1537-1543.

Finger S. E., Brisbin I. L. Jr, Smith M. H. and Urbston D. F. 1981. Kidney fat as a predictor of body condition in white-tailed deer. The Journal of Wildlife Management 45: 964-968.

Johns P. E., Baccus R., Manlove M. N., Pinder J. E., III and Smith M. H. 1977. Reproductive patterns, productivity and genetic variability in adjacent white-tailed deer populations. Proceedings of the Annual Conference of the Southeastern Association of Fish and Wildlife Agencies 31: 167-172.

Johns P. E., Cothran E. G., Smith M. H. and Chesser R. K. 1982. Fat levels in male white-tailed deer during the breeding season. Proceedings of the Annual Conference of the Southeastern Association of Fish and Wildlife Agencies 36: 454-462.

Johns P. E., Smith M. H. and Chesser R. K. 1984. Annual cycles of the kidney-fat index in a southeastern white-tailed deer herd. The Journal of Wildlife Management 48: 969-973.

Johns R. S. 1994. Influences of environmental variation, hunting, and population size on temporal patterns of fawn reproduction and influences of genetic variation female white-tailed deer reproduction on the Savannah River Site. M Sc thesis, Clemson University, Clemson, South Carolina: 1-37.

Lambiase J. T. Jr, Amann R. P. and Lindzey S. S. 1972. Aspects of reproductive physiology of male white-tailed deer. The Journal of Wildlife Management 36: 868-875.

Leberg P. Smith M. H. and Brisbin I. L. Jr 1992. Influence of sex, habitat, and genotype on the growth patterns of white-tailed deer. [In: The biology of deer. R. D. Brown, ed]. Springer-Verlag, New York: $343-350$.

Marchinton R. L. and Hirth D. H. 1984. Behavior. [In: White-tailed deer. L. K. Halls, ed]. Stackpole Books, Harrisburg, Pennsylvania: 129-168.

Miller K. V., Rhodes O. E. Jr, Litchfield T. R., Smith M. H. and Marchinton R. L. 1987. Reproductive characteristics of yearling and adult male white-tailed deer. Proceedings of the Annual Conference of the Southeastern Association of Fish and Wildlife Agencies 41: 378-384.

Mirarchi R. E., Scanlon P. F. and Kirkpatrick R. L. 1977. Annual changes in spermatozoan production and associated organs of white-tailed deer. The Journal of Wildlife Management 41: 92- 99.

Rhodes O. E. Jr, Novak J. M., Smith M. H. and Johns P. E. 1986. Assessment of fawn breeding in a South Carolina deer herd. Proceedings of the Annual Conference of the Southeastern Association of Fish and Wildlife Agencies 39: 380-388.

Rhodes O. E. Jr, Novak J. M., Smith M. H. and Johns P. E. 1991. Frequency distribution of conception dates in a white-tailed deer herd. Acta Theriologica 36: 131-140.

Riney T. 1955. Evaluating condition of free-ranging red deer (Cervus elaphus), with special reference to New Zealand. New Zealand Journal of Science and Technology 36: 429-463.

Sauer P. R. 1984. Physical characteristics. [In: White-tailed deer. L. K. Halls, ed]. Stackpole Books, Harrisburg, Pennsylvania: 73-90.

Scanlon P. F. and Lenker D. K. 1983. Male reproductive characteristics of white-tailed deer during November and December. Theriogenology 19: 855-867.

Schultz S. R. and Johnson M. K. 1992. Breeding by male white-tailed deer fawns. Journal of Mammalogy 73: 148-150. 
Scribner K. T., Wooten M. C., Smith M. H. and Johns P. E. 1985. Demographic and genetic characteristics of white-tailed deer populations subjected to still and dog hunting. [In: Proceedings of a symposium on game harvest management. S. L. Beasom and S. F. Roberson, eds]. Caesar Kleberg Wildlife Research Institute, Kingsville, Texas: 197-212.

Severinghaus C. W. 1949. Tooth development and wear as criteria of age in white-tailed deer. The Journal of Wildlife Management 13: 195-216.

Urbston D. F. 1967. Herd dynamics of a pioneer-like population. Proceedings of the Annual Conference of the Southeastern Association of Fish and Wildlife Agencies 21: 42-50.

Urbston D. F. 1976. Descriptive aspects of two fawn populations as delineated by reproductive differences. Ph D thesis, Virginia Polytechnic Institute, Blacksburg, Virginia: 1-104.

Received 30 June 1998, accepted 29 April 1999. 